Article

\title{
Key Drivers for High-Grade Recycling under Constrained Conditions
}

\author{
Jacqueline Cramer \\ Copernicus Institute of Sustainable Development, Utrecht University, Heidelberglaan 2, \\ 3584 CS Utrecht, The Netherlands; j.m.cramer@uu.nl
}

Received: 1 April 2018; Accepted: 24 April 2018; Published: 28 April 2018

\begin{abstract}
Various authors have analyzed the fundamental barriers that hamper the transition towards a circular economy, e.g., economic and business, regulatory and legal, and social. This analysis questions how, under these constrained conditions, high-grade recycling can still be implemented successfully in the Netherlands. The study compares five Dutch material flows: paper and cardboard, plastics, non-wearable textiles, building and demolition waste and mattresses. It is concluded that the following four key conditions should be in place, but need a tailor-made approach for each material flow: (1) adequate collection system/logistics; (2) guaranteed volumes of material supply; (3) clear market demand for and (4) quality guarantee of recycled materials. Moreover, the following five key drivers help circumvent the fundamental barriers and realize the four key conditions: (1) mobilizing power by change agents; (2) cooperation within the material chain; (3) well-attuned financial arrangement; (4) circular procurement; and (5) technological innovation (including redesign). These drivers follow a certain sequence in implementation and circumvent the fundamental barriers each in their own way. This empirical analysis complements the mostly conceptual or theoretical literature on the transition towards high-grade recycling and the circular economy in general. Based on this analysis a conceptual model is developed, in which the key conditions, the key drivers and fundamental barriers are linked. Whether the results also hold true for other countries than the Netherlands needs additional research.
\end{abstract}

Keywords: high-grade recycling; material flows; fundamental barriers; key conditions; key drivers; Dutch examples

\section{Introduction}

The transition towards a circular economy is a global challenge. Due to the worldwide increase of economic growth and the consumption of finite resources, society faces a growing scarcity of essential resources and a great burden on the environment. Therefore, a shift in our pattern of production and consumption is needed. By fostering a circular economy, the rates of extraction of natural resources, energy demand, emissions and other environmental harms can be reduced. In addition, the economic benefits for industry can potentially be increased and national political advantages created via a reduced dependence on imports and increased self-reliance [1,2].

The concept of a circular economy is not new, tracing back to different schools of thought [3-5]. The environmental economist Kenneth Boulding [6] introduced the idea of the economy as a circular system being a prerequisite for the maintenance of the sustainability of human life on Earth. This notion was adopted by other environmental economists [7]. Roots of the circular economy are also found in General Systems Theory [8] and various strands of ecologically oriented scholars propagating industrial metabolism [9], industrial symbiosis [10]; industrial ecology [11,12]; product life and services [13]; Cradle to Cradle [14]; and material efficiency [1]. 
Recently, the concept of a circular economy has gained momentum not only among scholars but also in government and business [15,16]. It expresses the feeling of urgency to move from a throw-away, linear economy towards a circular economy in which the following principles of a circular economy are respected [3]:

Principle 1: Preserve and enhance natural capital by controlling finite stocks and balancing renewable resource flows.

Principle 2: Optimize resource yields by circulating products, components and materials at the highest utility at all times in both technical and biological cycles.

Principle 3: Foster system effectiveness by revealing and designing out negative externalities.

Different levels of circularity can be distinguished, starting at the highest levels 'refuse' and 'reduce' aimed at preventing and reducing the use of resources. Next, priority should be given to the redesign and reuse of a product with an eye for circularity. This may vary from a complete circular redesign to the reuse of an existing product or maintenance, repair and improvement of a product or the reuse of a product for a different purpose. When product reuse is not possible or ecologically beneficial anymore [17]), one should strive for high-grade recycling of the material flows before ending at the lowest level, 'recover energy from waste'. Incineration and land-filling are not part of a circular economy but are still dominant in our society.

Despite the fact that product reuse is preferred above recycling [4], the need for improving the performance of recycling is evident. At present, the number of material flows being recycled with a high level of quality of the recyclate is low, while the potential for upgrading is high. By concentrating on high-grade recycling of material flows, more value is expected to be generated in terms of direct financial benefits [2,3] and indirect spin-off (namely, in creating more industry, more jobs, more innovation and greater environmental benefits). Despite all these potential opportunities, the implementation thus far is still limited.

Various authors have analyzed the fundamental barriers to move towards a circular economy. Allwood et al. categorize the following barriers to adopting material efficiency strategies [1]:

1. Economic and business barriers: (a) The costs associated with the environmental impacts of material and energy production (so-called externalities) are not reflected in the prices of materials; (b) Reuse and recycling would compete for the same stream of material; (c) Business may be locked into the legacy assets that were developed; $(\mathrm{d})$ Business models in production companies are oriented towards growing sales volumes.

2. Regulatory and legal barriers: (a) Existing legislation can lead to materially inefficient practices, for instance scrappage schemes, favorable tax reductions, health and safety regulations; (b) Lack of government certification for reused materials; (c) Standards which prescribe a certain material composition instead of a material performance; (d) Lack of legal obligations for information provision; (e) Limitations in the extended producer responsibility legislation.

3. Social barriers: (a) Fashion rather than form or function determines the end of life of many goods;

(b) Convenience has become a major driver of consumption; (c) The 'throw-away' society treats as normal the discard of materials with reuse value; (d) Pervasiveness of marketing.

Söderholm and Tilton [18] also identify fundamental barriers for material efficiency but frame these in terms of the market failures. They identify: (a) Inefficient market prices due to the absence of internalized environmental costs; (b) Different types of information failures, not the least the presence of asymmetric information; (c) Innovation-related market imperfections; and (d) Technological externalities that could affect, for instance, the reuse or recycling of products. These barriers overlap with those mentioned by Allwood et al. [1], although they do not explicitly refer to information failures.

The barriers cited above can only be removed by fundamental changes in national, EU or even international policies, along with consumer and business behavior. According to Allwood et al. [1] these changes relate to the following key drivers: business opportunities; government interventions; and consumer drivers. Such change processes take time and will therefore not be solved with short 
notice. Despite these constrained conditions, attempts are made by companies to leverage new business opportunities by improving their circular performance. Which barriers they encounter in practice has recently been studied by few authors. Ritzen and Olundh Sandström [19] have summarized these studies and listed the following barriers: (1) Financial (measuring financial benefits of the circular economy, financial profitability); (2) Structural (missing exchange of information, unclear responsibility distribution); (3) Operational (infrastructure/supply chain management); (4) Attitudinal (perception of sustainability, risk aversion); and (5) Technological (product design, integration into production processes). Ritzen and Olundh Sandström conclude that the literature so far is mostly conceptual or theoretical and although similar relevant barriers are identified in research, they are rarely empirically based ([19], p. 11). This also holds true for the mechanisms to promote circular economy.

This paper aims to bridge the above knowledge gap by focusing on an empirical study of the key drivers of change towards high-grade recycling in practice. At this moment, it is assumed that the fundamental constraints mentioned by Allwood et al. [1] cannot be solved in the short term. Moreover, the hypothesis is that the way in which these key drivers need to be shaped may vary. The latter view is based on the analysis of Hagelüken et al. who concluded that a one-size-fits-all approach would not be effective in realizing the transition towards a circular economy [20]. Therefore, five different material flows are compared: paper and cardboard, plastics, non-wearable textiles, building and demolition waste and mattresses. The analysis focuses on the experiences in the Netherlands, as this country is one of the European leaders when it comes to processing and recycling waste. This is due to a comparatively long history of paying attention to closing the loops of products and materials, since the 1980s [21]. At present, The Netherlands recycles $78 \%$ of their waste, incinerates $19 \%$ and landfills only $3 \%$. However, although considerable progress has been made, the Netherlands still has a long way to go in grasping the full potential of a circular economy.

\section{Methodology}

This study focuses on five specific material flows which all have the potential for higher grade recycling. These cases are selected in close cooperation with representatives of material chains who were eager to improve their performance. They asked the author of this paper to organize collaborative workshops (so-called Circular Economy Labs) to foster the potential for increasing the value of recycling for their material chain. As they trusted the independent and at the same time critical attitude of the moderator, they hoped to gain inspiring new insights and forms of cooperation that they could not achieve by themselves. For the author of the paper, each workshop provided an opportunity to mobilize all actors in the material chain, along with critical outsiders to generate both novel ideas and pragmatic initiatives to enhance the performance of the material chain. The material chains selected represented a wide range of cases in terms of stage and performance of recycling and therefore offered an interesting scope for cross-case comparison.

The preparation of each workshop started with a brainstorming session together with the representatives of the material flow that asked for cooperation. They discussed the fundamental barriers to increasing the value of recycling, referred to relevant documents and mentioned the principal actors involved. Next, the author of this paper made an extensive document analysis and then contacted 10-12 key actors identified for an interview by phone of about $45 \mathrm{~min}$ on next steps in high-grade recycling. The main question was which key drivers help circumvent the fundamental barriers to high-grade recycling they face. Minutes were made of each interview. All interviews were summarized in a set of major issues that formed the guidelines for each collaborative workshop.

The objective of the collaborative workshop was to explore the key conditions and drivers under which high-grade recycling will be increasingly possible. Each two-hour workshop was attended by on average a hundred participants and was set up in a similar manner. It consisted of two panel debates proceeded by a pitch of a key stakeholder triggering the dialogue. The three to four members of each panel were carefully selected in the preparatory phase based on their frontrunner role in the material chain. These panel members were innovation or business managers of primary producers, customers 
and recyclers, directors of sector organizations, sustainability business managers, scientific experts, young high potentials, innovative startups or NGOs. Panel one discussed the fundamental barriers of moving towards high-grade recycling and the key conditions for improvement, while the second panel jointly formulated the key drivers that help circumvent fundamental barriers to high-grade recycling. The audience was actively invited to share their experiences. To make sure that representatives of the particular material flow were present in the audience, the assistant of the moderator approached a number of people to join. At the end of the workshop, the moderator summarized the constraints and drivers of change and asked the panel and audience for additional comments. From each workshop a video, written report and an article for the Dutch journal Milieu (Environment) were made [22]. The information gathered in the preparatory phase and during the workshop enabled the analysis presented here. The execution of the five labs took place in a time span of a little over two years: paper and cardboard (28 January 2014), plastic (2 December 2014), textile (30 March 2015), construction and demolition (28 November 2013 and 25 September 2014), and mattresses (25 January 2016).

\section{Analysis of Five Material Flows}

\subsection{Fundamental Barriers}

The transition towards high-grade recycling of the five material flows studied is hampered by a variety of fundamental barriers. All three types of barriers, distinguished by Allwood et al. [1], are occurring here: economic and business barriers; regulatory and legal barriers; and social barriers. However, some have more impact than others.

With respect to the economic and business barriers, the problem of not taking into account the costs associated with the environmental impacts (so-called environmental externalities) has been frequently addressed in the literature [23,24], but also comes to the fore in the five cases studied here. This often leads to higher prices for recyclates than for virgin materials, especially in highly competitive international markets. Moreover, the recycling industry has to compete with well-established production companies that tend to focus on their traditional business model and existing technologies. New initiatives in the supply chain are therefore hard to get off the ground [25]. This may lead to technological externalities [18] having an impact, where one firm manufactures a product in a way that increases the cost of recycling or reuse for the downstream processor. This holds true, for example, in the use of multi-layer plastics for food packaging, which is incompatible with mechanical recycling. The same goes for the use of plastic lined paper and inking technologies in paper printing which then requires new technical solutions in paper recycling [18]. A less visible issue is competition between reuse and recycling for the same stream of material, for instance in paper and pulp and partly in plastics and non-wearables. Here, the material flow is in a stage that does not conflict anymore with product reuse.

Regulatory and legal barriers also occur in all five cases. This is due to the often mentioned mismatch between current legislation and legislation aimed at achieving a circular economy [26-28]. While the barriers are generally the same, their shortcomings are specific for each material flow. In order to use a recyclate as a resource, the material flow needs to have the status of non-waste [29]. In all five cases this problem can be overcome. However, the responsibility is on the recycler to prove the quality of the recyclate, making sure it is not contaminated. This is particularly hard in those cases where the material flow is more complex and/or contains additives and other specific substances (e.g., in the plastics realm) [29]. Furthermore, existing standards prescribing a certain material composition instead of a material performance can hinder the introduction of new materials or practices. This is especially the case in highly regulated markets such as the building and construction sector. As long as hardly any legal obligation exists for information disclosure in the product chain, the above problems will remain hard to solve [29]. Similarly, limitations in extended producer responsibility legislation can hamper cooperation in the product chain to enhance circularity of products and materials [30]. This holds true for all five cases. The social barriers mentioned by among others Allwood et al. [1] 
and Ruggieri et al. [26] also play a role in each of the five cases, but some of them are less dominant. This is due to the fact that the five cases focus on the collection and high-grade recycling of material flows that are discarded and not on product reuse. Therefore, fashion and pervasiveness of marketing are less important barriers than the other two social barriers mentioned by Allwood et al. [1]: convenience as a major driver of consumption and the 'throw-away society' that treats as normal the discard of materials. These latter two barriers refer to existing consumption patterns which trigger more rather than less use of primary raw materials. Beyond the social barriers Allwood et al. mention, there is also the disinterest of some consumers in separating their waste according to the rules set by local government. As a result, the material flows collected can be contaminated or hard to separate at a later stage.

Bearing in mind these fundamental barriers, we will analyze whether circular initiatives can be successfully undertaken when it comes to paper and cardboard, plastics, non-wearable textiles, building and demolition waste, and mattresses. The key conditions for implementing high-grade recycling will be discussed for all five cases. Moreover, the key drivers that help circumvent fundamental barriers to high-grade recycling will be identified for each case. The results form the basis for a cross-comparison and provide the opportunity to draw general conclusions on the possibilities to implement high-grade recycling of material flows under constrained conditions.

\subsection{Paper and Cardboard}

At present, $85 \%$ of the paper and cardboard is being recycled in the Netherlands. The key challenge here is finding a proper balance between the supply of recycled material and the processing capacity. In the Netherlands, the price of the recycled material is regulated as the paper and cardboard industry guarantees a minimum price. When the price of the recycled material drops below this point, the loss is on the account of the industry, which as a result provides the recyclers sufficient certainty. Due to this financing system, the high quality of recyclates and a long-standing tradition of separate collection, paper and cardboard products already have achieved a high recycling rate in the Netherlands and other countries as well. Therefore, the Ellen MacArthur Foundation calls the paper and cardboard sector a 'Golden oldie' with a high potential for becoming fully circular [31].

What are the next steps in closing the cycle of paper and cardboard together with supply chain partners? According to the R\&D manager of one of the main paper producers, some material flows are not yet properly separated when discarded, but instead are put in the mixed bins. By setting up a collaboration between customer and supplier, these flows can also be recycled by the pulp and paper industry. To ultimately close the paper and cardboard loop completely, breakthrough technologies are needed, which transform the current production into bio-refineries. The advantage of paper and cardboard is that it consists of a renewable material that in principle can be produced sustainably. Besides wood other renewable resources can be used as well. For instance, cardboard can be made from the stem of tomato plants and packaging boxes from the leaves. All components of wood and other bio-crops can be used: cellulose for the production of ethanol for instance, lignin for phenols and hemicellulose for fiber-additives, hydrogels, resins and inorganic ingredients for other applications. This means an opportunity for a complete redesign of the current pulp and paper industry in an integrated sector that produces food, resources, fuels, materials and biodegradable products out of biomass and waste streams. In such a bio-based value chain, a circular loop can be created in which the customer may lease fibers while the producer of the resources remains the owner of the fibers. Although all these developments are still hopes for the future, several panel members of the workshop were advocating this path forward.

\subsection{Plastics}

Until 2007 the Netherlands only recycled company specific plastics, and PET bottles collected via a deposit system. Since then the national government has set up a collection system for plastic packaging discarded by households. This system, called the Plastic Hero was financed through an additional packaging tax, which generated the money for collection via municipalities and for the first 
step of recycling, the sorting of different plastics. The original objective was to achieve a recycling rate of $52 \%$ of the household packaging plastics by 2022. However, the Plastic Hero system was so successful that this target was already reached in 2017.

As the possibilities for plastic recycling increased, recyclers got interested in investing in facilities to sort the different types of plastics. The first recycling plant was established in the area of Rotterdam. However, at present two significant constraints are holding up the acceleration of plastic recycling. First, coordinated procurement policies are lacking among municipalities on how to guarantee investors a continuous supply of large volumes of household plastics so that they are willing to install a plant. As municipalities are autonomous in selecting a recycler, this certainty is not evident. Secondly, sufficient demand for recycled plastics is needed in order to create a viable business case for the recycler. This implies that customers need to be willing to use recycled plastics in their products and guarantee a steady demand. Obstacles for customers also play a part, when the price of recycled material is higher than virgin or the quality of the recycled plastics cannot be guaranteed. These latter obstacles are not only encountered for household plastics but also for plastics generated by business. During the workshop, a director of a plastic recycling company stated that customers fear contamination in plastic recyclate and therefore tend to follow the stringent requirements set by EU regulation. He argued that this regulation could be modified to incorporate circularity, but that takes time. It requires revised product quality standards and/or the adaptation of the Waste Framework Directive to get a product status for the recycled material.

In order to realize a consistent demand for recycled plastics, circular procurement is an alternative pathway. Philips provides a good example, as this company has implemented a policy to include recycled plastic in consumer products [32]. According to the sustainability manager of Philips present at the workshop, his company cooperates with suppliers who can guarantee the quality of their recyclate. Another manner to increase the demand for recyclates mentioned at the workshop is the setting of standards by the government regarding the recycled content in products, for instance in packaging. According to the panel members, when large volumes of packaging material at least partly consist of recycled plastic, high-grade recycling will speed up.

All efforts mentioned above will be even further enhanced when the plastic material chains are redesigned, technological innovations are developed in view of circularity, and more plastic products are leased instead of sold. In the latter case, the producer remains responsible for the product, which means to take continuous care of its quality and durability.

\subsection{Non-Wearable Textiles}

The Netherlands has a long tradition of collecting discarded clothing. About half of this resource stream can be reused as clothes but the rest are non-wearable textiles, which are incinerated or at best used as, for instance, insulation material and filling of cushions. The challenge is how these end-of-life textiles can be brought back into the cycle with higher value. This requires the following steps: separating these textiles into different kinds of materials, reworking the textiles into fibers, and then spinning new materials thereof. Even higher results can be gained when circularity is included in the design of new clothes, for instance by using mono-materials instead of materials composed of different fabrics and by avoiding the loss of plastic microfibers during washing.

During the workshop on how to get the high-grade recycling of non-wearable textiles off the ground, the views were remarkably similar. A main driver for success mentioned was the adoption of a collective approach in which the material chain jointly establishes a business case. Besides collecting high volumes of end-of-life textiles, the main constraint is selling the recycled textiles, as they are more expensive than virgin fibers.

How can such circular initiatives be taken? A good example was provided at the workshop by the representative of the House of Denim. This company has developed an innovative concept for recycled jeans, called Red Light Denim. This stands for 'Made in Amsterdam' recycled jeans produced from jeans that are collected in Amsterdam and separated from other textiles in a factory near Amsterdam. 
The non-wearable denim is remade into fibers, then made into recycled denim and mixed with virgin material to make new jeans. This process saves $600 \mathrm{~L}$ of water per pair of jeans and reduces the environmental burden substantially.

Scaling up this denim example is possible by organizing a critical mass of supply and demand. According to participants at the workshop, a new facility to rework discarded textiles into fibers needs a volume of about 7,000-10,000 tons per year to be profitable in the Netherlands. Through scale and continuity in supply, cost reduction is possible. Moreover, the following drivers need to be taken into account: First, the contracts between textile collectors and municipalities should be changed. Instead of only getting paid for collecting and selling second-hand textiles, the municipalities should also include high-grade recycling of non-wearable textiles. In addition, circular procurement can play an important role. A prime mover in the Netherlands was the Ministry of Defense. The procurement manager of this Ministry said at the workshop that he introduced a lease concept for the continuous supply of defense clothing in combination with a recycling scheme. This circular initiative is now being followed by the national police and fire brigade. Via this approach, the government can create a market of company clothing of about 200 million euros according to the manager of the Ministry of Defense. Similarly, other government or industry related organizations can set up such circular initiatives.

\subsection{Construction and Demolition Waste}

In the Netherlands about $40 \%$ of all waste streams is related to the construction sector. Policies for reuse and recycling of these waste streams were already implemented in the late 1980s [33]. However, efforts mainly focus on the low-grade application of recycled materials, for instance as asphalt under-layers [34]. Compared to 25 years ago, the technological possibilities for resource-efficient reuse and recycling have been enhanced. This holds true, for example, for the recycling of concrete, granulate, bituminous roofing, metals, glass and also for the reuse of products such as wood, natural stone, walls, facade slabs and other, still usable products. Therefore, the challenge is to demolish buildings in a more circular manner, increasing the quality of the material flows such that they are applicable for high-grade applications, thus creating sufficient supply and demand for them.

In the Netherlands, the Rotterdam "Circle City" project is a prime example of a frontrunner initiative [34]. A consortium of four parties joined forces in the Rotterdam neighborhood Hoogvliet to close the loop of building materials. These were a social housing corporation, a demolition firm, a cement producer and the municipal cleaning department. They showed that in principle, practically all material flows can be reused and recycled. After the circular demolition of the houses, almost all the building materials were reused in the construction of new buildings. On the basis of research on their findings [35,36], it could be concluded that cooperation among partners in the chain was the key to success. In this way, it can be safeguarded that circular demolition does not have to be more expensive. Moreover, several other advantages became visible, e.g., risks and information are shared, synchronizing among the parties takes place and innovation is jointly utilized. Additionally, employment can be created for people that were previously jobless for a sustained period of time.

Despite these opportunities, however, the scaling up of this circular initiative to a national level is still a ways off in the Netherlands. Based on research $[35,36]$ and on a workshop dedicated to this issue, the following constraints came to the fore. First, the building and construction sector is not familiar enough with the economic and ecological merits of the Circle City approach to dare taking up this challenge. This knowledge gap is now being tackled by setting up 'communities of practice' - networks of interested stakeholders that can learn from each other by exchanging knowledge and experience. A second driver that is lacking, is cooperation in a consortium of companies who are willing to disclose information and trust each other. This cooperation needs to be accompanied by the implementation of new financial and organizational arrangements as practiced by the Rotterdam 'Circle City' project. Moreover, the need is expressed for a virtual marketplace where supply and demand of recycled materials can be geared to one another. In addition, physical locations are asked for to store recycled materials temporarily. 
In order to increase the level of ambition in circular demolition and construction practices, bidders such as government and industry can also play a crucial role [33]. This was confirmed at the workshop. Bidders can formulate specific circular requirements in their procurement policies which enhance high environmental, social and economic performance. Moreover, they can promote the use of recycled materials in new buildings and the design of sustainable buildings. Technological innovations, including the redesign of construction practices, will push such developments even further.

\subsection{Mattresses}

In the Netherlands, about 1.5 million mattresses are discarded yearly, of which $85 \%$ is incinerated. Because of their high volumes and specific material composition (consisting of latex, polyurethane, steel and textiles), mattresses form an interesting waste stream to reuse and recycle at high grade.

At present, reuse of discarded mattresses is limited in the Netherlands. Before reselling, all mattresses need to be cleaned for hygienic reasons, leading to quality reduction. Only a few pro-active mattress producers have started to get interested in 'design for reuse and recycling', i.e., the adaptation of easily recyclable materials and disassembly of mattresses. Examples of such innovative redesigns are the replacement of the mattress textile and product reuse of the steel construction of the mattress. Ultimately, such innovative initiatives being developed can lead to an increase in product reuse and recycling activities. However, at present, municipalities' primary concern is the high volumes of currently discarded mattresses. They cause problems in incinerators and therefore should preferably be recycled.

Recycling of mattresses is still in its infancy. Only two specialized recyclers have taken the lead in mattresses' recycling and have been able to sell the recycled raw material to producers (e.g., by re-using it for insulation). How can such initiatives be up-scaled? This was the central question of the workshop on high-grade recycling and reuse of mattresses.

The panel members summarized the following key conditions: First, the separate collection of discarded mattresses (including the logistics thereof) has to be organized and paid for. While the high costs of separate collection form a clear barrier, the generation of high yearly volumes of mattresses guarantees sufficient supply. However, the success of separate collection and logistics largely depends on those discarding and collecting mattresses, particularly the municipal waste collectors, professional suppliers (such as hospitals and nursery homes) and the more than 900 Dutch specialty retailers. As recyclers can negotiate long-term contracts directly with those chain partners, they can secure their own market of supply without the intervention of local governments. Additionally, a good spread of recycling facilities should be established in order to limit the distance between the disposal and recycling.

Secondly, a major constraint is the low price that recyclers get for the recycled materials. They have to compete with producers of recycled materials from e.g., car chairs and virgin polyurethane producers. Due to the oversupply on the market, the prices collapsed by more than $90 \%$ in five years' time. Due to a lack of money, the recyclers cannot at the moment increase their economic efficiency through technological innovations.

To overcome the constraints mentioned above the implementation of extended producer responsibility was proposed at the workshop. This implies that the mattress producer remains responsible for the product during its entire lifecycle. To finance the system, the price of a mattress needs to incorporate the costs of recycling and logistics and of technological innovations in the whole product chain. During the circular economy lab, representatives of the whole mattresses' chain expressed the intention to join forces and set up such an extended producer responsibility system voluntarily. This circular initiative is currently being prepared to assess its potential.

\section{Comparison of the Five Material Flows}

In comparing the five material flows analyzed above, the following conclusions can be drawn:

First, four key conditions can be identified that need to be in place to realize high-grade recycling. These are: 
a. An adequate collection system, including the accompanying logistics to provide recyclers material flows that they can recycle. This can be a separate collection system at the curb site or it may be a recovery system that separates material flows in a dedicated facility.

b. Guaranteed volumes of material supply to elicit the interest of recyclers in investing in production facilities.

c. Clear market demand for the recycled materials to make sure that the recyclers get a return on their investment.

d. A guaranteed quality of the recycled materials to generate high-grade materials that are accepted by the market and of high value.

In Table 1 the main results have been summarized for each material flow. The table indicates whether the key conditions are met $(\sqrt{ })$ or not met $(\times)$.

Table 1. Cross comparison of five material flows and key conditions.

\begin{tabular}{|c|c|c|c|c|c|c|c|}
\hline & & & \multicolumn{5}{|c|}{ Material Flows } \\
\hline & & & $\begin{array}{l}\text { Paper and } \\
\text { cardboard }\end{array}$ & Plastics & $\begin{array}{l}\text { Non-wearable } \\
\text { textiles }\end{array}$ & $\begin{array}{l}\text { Construction/ } \\
\text { demolition }\end{array}$ & Mattresses \\
\hline \multirow{3}{*}{$\begin{array}{l}\text { Key Conditions } \\
\text { for High-Grade } \\
\text { Recycling }\end{array}$} & $\square$ & Guaranteed volumes of supply & $\checkmark$ & $\times$ & $\times$ & $\times$ & $x$ \\
\hline & $\square$ & Market demand for recycled materials & $\checkmark$ & $\times$ & $\times$ & $\times$ & $\times$ \\
\hline & $\square$ & Quality guarantee of recycled materials & $\checkmark$ & $x$ & $x$ & $x$ & $\times$ \\
\hline
\end{tabular}

Note: $\checkmark$ Condition met; $\times$ Condition not met.

Table 1 shows that for paper and cardboard the key conditions are met, while for the other material flows all conditions still need to be accomplished, except for the adequate collection system/logistics for plastics.

Secondly, five key drivers can be distinguished that help circumvent fundamental barriers to high-grade recycling:

a. Mobilizing power of change agents. In all cases change agents play a crucial role in mobilizing actors in the material chain to set up circular initiatives geared towards product reuse and high quality recycling. A change agent is defined as a supply chain member who is seeking to drive or subvert a change agenda [37]. Without such actors taking the lead, change processes are hard to get off the ground.

b. Cooperation among the partners in the material chain. In all cases, partners need to exchange information and work jointly towards high-value recycling in order to be effective [4]. These partners include not only the companies involved but also municipalities, knowledge institutes and other relevant actors.

c. Well-attuned financial arrangements. The five cases show the importance of developing a business case which is acceptable and interesting for all actors in the material chain.

d. Circular procurement policies of bidders. Preferential purchasing by governments and companies can actively influence the ambition and actual practice of partners in the material chain [38]. When bidders demand a specific level of circularity, they set the standard for the whole material chain. This was also the case in the five material flows analyzed above.

e. Technological innovation, including redesign. To achieve more far-reaching results in the reuse of products and high-grade recycling of materials, technological innovation is indispensable [4]. More effective techniques to collect, separate and recycle discarded materials can improve the quality and price of the recycled materials. Additionally, redesigning products with an emphasis on circularity can lead to the development of products and services that fit much better in a circular economy.

In Table 2 the main results have been summarized for each material flow. The table indicates whether the drivers are in place $(\sqrt{ })$ or not $(\times)$. 
Table 2. Cross comparison of five materials flows and key drivers.

\begin{tabular}{|c|c|c|c|c|c|c|}
\hline & & \multicolumn{5}{|c|}{ Material Flows } \\
\hline & & $\begin{array}{l}\text { Paper and } \\
\text { cardboard }\end{array}$ & Plastics & $\begin{array}{l}\text { Non-wearable } \\
\text { textiles }\end{array}$ & $\begin{array}{l}\text { Construction/ } \\
\text { demolition }\end{array}$ & Mattresses \\
\hline \multirow{5}{*}{$\begin{array}{l}\text { Key Drivers That Help } \\
\text { Circumvent Fundamental } \\
\text { Barriers to High-Grade } \\
\text { Recycling }\end{array}$} & 1. Mobilizing power by change agent(s) & $\checkmark$ & $\checkmark$ & $\times$ & $\times$ & $\times$ \\
\hline & 2. Cooperation in material chain & $\checkmark$ & $\checkmark$ & $x$ & $\times$ & $\times$ \\
\hline & 3. Well-attuned financial arrangements & $\checkmark$ & $\checkmark$ & $x$ & $x$ & $x$ \\
\hline & 4. Circular procurement & $\checkmark$ & $x$ & $x$ & $\times$ & $\times$ \\
\hline & 5. Technological innovation (including redesign) & $\times$ & $\times$ & $x$ & $x$ & $\times$ \\
\hline
\end{tabular}

Note: $\checkmark$ Key driver in place; $\times$ Key driver not in place.

Based on the cross-comparison of five material flows, it can be concluded that similar key drivers need to be in place to meet the key conditions mentioned in Table 1. Most advanced is the paper and cardboard recycling sector. While the basic conditions are met, even higher performance levels can be achieved in the future through innovation and redesign. In principle, such more ambitious steps can also be prepared in the case of the four other material flows. However, in these latter cases, a number of key drivers still need to be put in place to get high-grade recycling off the ground at large scale.

The high-grade recycling of plastic material flows is progressing. Despite the existence of mobilizing power by change agents, well-attuned financial arrangements via a national tax scheme and cooperation of some partners in the material chain, the performance is constrained for a number of reasons. To guarantee sufficient volumes of supply for a potential investor in a recycling facility, cooperation is needed among municipalities as bidders. Currently, they organize their own outlet instead of joining forces. Moreover, their procurement policies focus on quantity rather than quality of the recycled materials. This is encouraged by the national subsidy scheme which rewards municipalities for their efforts on the basis of quantity of plastics collected. Due to the lack of certainty about the quality of recycled plastics, market demand is still lacking. These problems can only be solved by circular procurement, in which supplier and customer closely cooperate.

The high-grade recycling of non-wearable textiles is also on the way. Because of the existence of a collection system, adequate logistics and financial model for second-hand clothes, non-wearable textiles can rather easily be included. Here too, cooperation among municipalities is needed to guarantee sufficient volume and help create market demand via circular procurement. Successful initiatives of change agents have shown the possibilities thereof. Compared to plastics, which often contain specific contaminants, the quality guarantee for textiles is less problematic.

The circularity of construction and demolition material flows is still limited [39]. Most important is the lack of circular procurement initiatives. When bidders require circular demolition and construction of buildings and infrastructure, the market for recycled materials will be created. At the same time, it will trigger new collection systems and logistics. As contractors need to respond to circular procurement policies, they have to work out a financial model that is acceptable to all partners in the chain. The example of Rotterdam Circle City project and others following a similar approach show that change agents can mobilize the material chain in jointly realizing circular initiatives. Sufficient volumes of supply can quite easily be organized at the local level and do not need cooperation among municipalities as in the case of plastics and non-wearable textiles. Quality assurance, however, is a key issue because the building sector is heavily regulated. New materials or recyclates often require adjustment of standards.

Finally, the circularity of mattresses is still in its infancy. Although two recyclers are active in the Netherlands, the high-grade recycling is not yet ready to get off the ground at large scale. Here, a positive business case cannot be developed unless a joint initiative is taken, as is presently the case. Change agents take the lead in preparing a voluntary producer responsibility initiative, as a great majority of partners in the product chain is inclined to favor this solution. When this initiative is successful most key conditions are met. As the collectors of mattresses can directly deal with their customers, they can set up a proper collection and logistics system and assure enough volume of supply to be profitable. Quality guarantee is less problematic compared to other cases because of the 
rather uniform and distinguishable composition of the materials. Similarly, most key drivers will also be in place: cooperation in the product chain, an acceptable financial model and an agreement on technological innovation, including eco-design. Additionally, circular procurement or other measures should be initiated to guarantee market demand for the recycled materials. Whether the proposed producer responsibility system will be effective, considering its limitations, remains to be seen [30].

In sum, despite the commonality in key conditions and drivers, the study reveals the need of a tailor-made approach for each material flow. The specific manner in which key conditions are met varies. The particular collection system and logistics differ depending on the actors that dispose of the material flow: citizens, companies or (semi) government bodies. The guaranteed volumes of supply relate to the scale at which the business case is profitable. Market demand for recycled materials especially depends on price and guaranteed quality. The latter is critical in some cases (e.g., plastics, building and construction material flows), while it plays a less dominant role in others (e.g., non-wearable textiles). Similarly, for each material flow, the specific manner in which these drivers can be effective differs. For example, in some instances (e.g., plastics, non-wearable textiles) collaboration between municipalities as bidders is of more importance than in other cases (e.g., building and construction material flows). Furthermore, arrangements to finance high-grade recycling are case specific as well. Finally, the procurement policies of each material flow include specific performance requirements. In that sense, the key drivers need to be customized for each material flow. This is particularly the work of change agents that take the lead in mobilizing the material chain in a circular direction.

The analysis of the cases shows that the introduction of the five key drivers often follows a logical order. (1) Change-agents with mobilizing power should come to the fore. They approach relevant actors in the product chain to join forces and cooperate in a new initiative; (2) The actors should agree upon the need to promote high-grade recycling and be willing to exchange necessary information; (3) This cooperation can then lead to the development of well-attuned financial arrangements; (4) Circular procurement can be effective in putting extra pressure on the initiative for high-grade recycling in the product chain or can be a trigger for the contractors to establish cooperation among relevant actors in the material chain. In the latter case circular procurement precedes steps 2 and 3; (5) Finally, when actors in the product chain aim for an even higher overall performance, technological innovation (including eco-design) becomes important. Only when all key drivers are in place, the impact will achieve its maximum potential.

The logical order becomes apparent when we look at how each driver helps circumvent the fundamental barriers that hamper high-grade recycling, viz. economic and business barriers, regulatory and legal barriers, and social barriers.

1. The mobilizing power of change agents sets in motion the transition process and thus influences all three barriers. However, only when other key drivers are in place, circular initiatives can get off the ground.

2. Cooperation in the material chain triggers joint action of relevant actors and can push to the background all three fundamental barriers. Regulatory and legal barriers are eliminated when the quality of the recyclate is agreed upon by targeted customers. Close contact between suppliers and customers of the particular recyclate is therefore crucial. Social barriers can turn into opportunities when the whole material chain including the consumers and society at large, are part of the change process. Municipalities have an important role to play in involving their citizens in separate waste collection and the communication about the merits thereof. Thus, cooperation in the material chain also includes other actors than the business community.

3. Eliminating economic and business barriers is usually part of the cooperation agreement but will be reinforced when well-attuned financial arrangements are made. By developing a dedicated business-model in which costs and benefits are evenly shared, the actors involved can jointly develop a viable business case and circumvent economic and business barriers. 
4. Although the cooperation within the material chain and well-attuned financial arrangements are the most influential drivers to implement circular initiatives, the change process can be enhanced or triggered when circular procurement is put in place. Through this driver the market is forced to develop circular propositions. As contractors have to meet specified circular requirements at a fixed price, economic and business barriers can be overcome. Moreover, when quality aspects of the recyclates are included in the procurement requirements, regulatory and legal barriers are less problematic as well. Social barriers are not directly influenced by circular procurement.

5. Finally, the key driver 'technological innovation (including eco-design)' can influence all three fundamental barriers in a positive manner. Through innovation the economic, ecological and social performance of the material chain can be strongly improved, when all these aspects are taken into account in the design stage of the innovation. This implies that high-grade recycling of the material flow can become more economically effective, less burdensome for the environment and more beneficial for society, which also reduces the fundamental barriers.

Figure 1 presents the conceptual model that visualizes the key drivers that help circumvent fundamental barriers and realize the key condition for high-grade recycling.

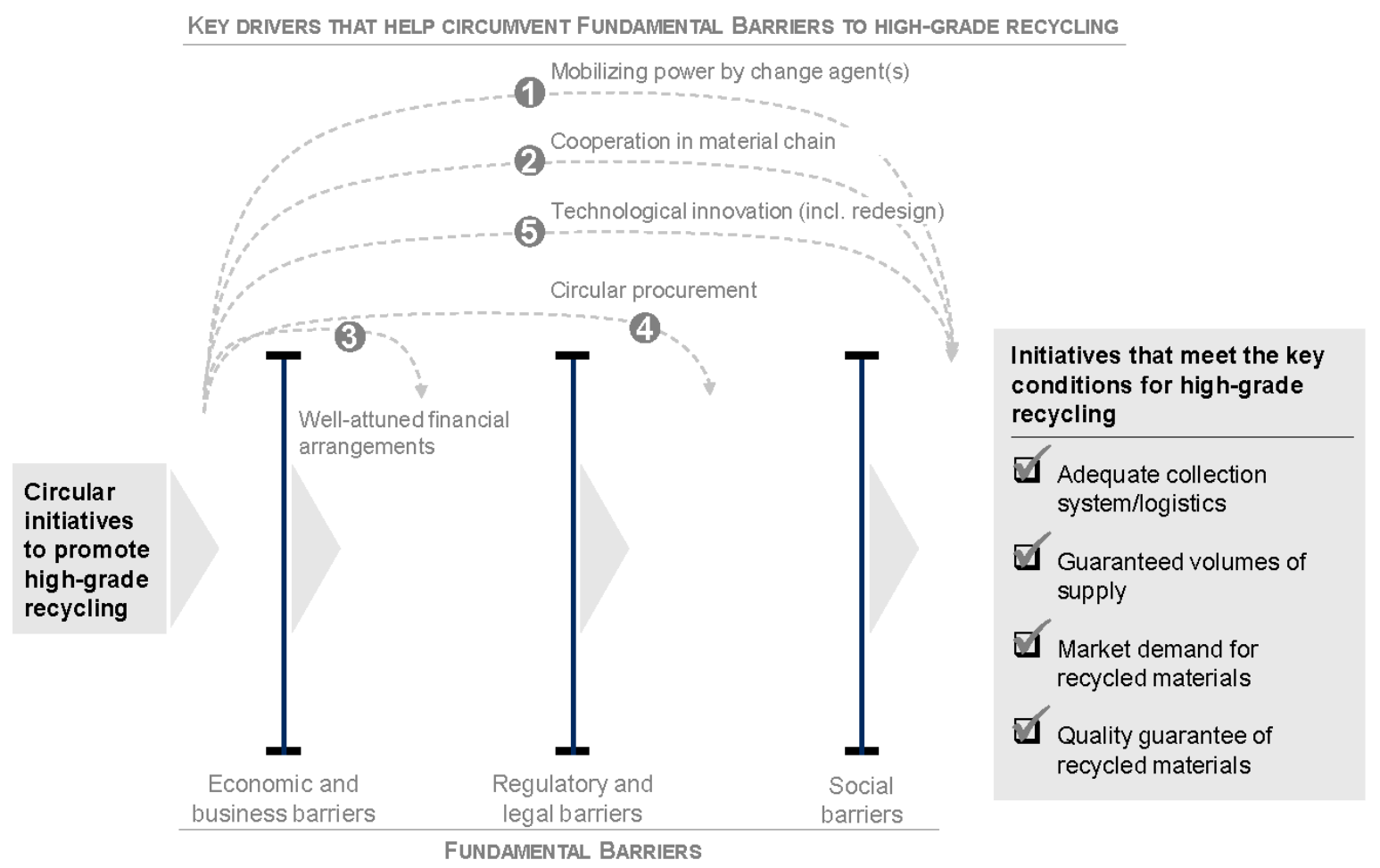

Figure 1. Key drivers for high-grade recycling that help circumvent fundamental barriers.

\section{Conclusions}

Fundamental barriers hamper the transition to high-grade recycling, viz. economic and business barriers, regulatory and legal barriers, and social barriers. Obviously, circular initiatives will accelerate much faster if these fundamental barriers are removed. However, the political reality is that finding solutions for such fundamental barriers takes a lot of time and political will. Although the fundamental barriers will therefore not be overcome in the short term, this analysis shows that circular initiatives to promote high-grade recycling can still be undertaken.

Based on an empirical study of five Dutch material flows it can be concluded that four key conditions need to be met, viz. an adequate collection system and logistics; guaranteed volumes of supply; market demand for recycled materials; and quality guarantee of recycled materials. 
The particular manner in which these key conditions are fulfilled varies among the different cases. The analysis also reveals that in all cases five key drivers help circumvent fundamental barriers and realize the key conditions for high grade recycling. However, these key drivers should be tailor-made as well.

The most influential key drivers to implement high-grade recycling are cooperation in the material chain in combination with new financial arrangements. While cooperation in the material chain can help overcome all three fundamental barriers, well-attuned financial arrangements can reinforce a viable business model, which circumvents fundamental economic and business barriers. When actors in the material chain jointly agree upon how to organize and finance high-grade recycling, many obstacles can be taken way. This conclusion corresponds with the analysis of Ruggieri et al., who developed a meta-model of inter-organizational cooperation for the transition to a circular economy [26]. An additional accelerator or even a trigger to circumvent fundamental barriers is circular procurement. The bidder can steer in the direction of high-grade recycling by formulating circular performance requirements at a fixed price. In this way, contractors get certainty about price and quality performance, which helps to circumvent the economic and legal barriers.

As new forms of cooperation do not get off the ground easily, change agents are needed to mobilize and orchestrate the change process. Therefore, this key driver is important to guide the process, but cannot circumvent the fundamental problems by itself. This also holds true for the last key driver 'technological innovation (including eco-design)'. This driver can catalyze new innovations, which are targeted at high-value recycling, eco-design and circular initiatives in the material chain in general. Such innovations accelerate the transition process and can alleviate all three fundamental barriers at the same time.

Thus, every material chain requires a specific way of organizing and financing circular initiatives depending on the composition of partners in the chain, the role of local government and the specificities of the material flow at stake. It requires a case-by-case orchestration, which surmounts the individual interests and aims for a solution that favors all partners in the product chain. This is a new form of governance in which all relevant stakeholders are involved and have to act according to the rules jointly formulated. In the Netherlands, this type of governance is called 'transition management' [40]. It is the management of change processes, which are directed towards the development of a new economic system. The analysis presented here fits in this tradition.

The major contribution of this analysis to the literature is the empirical underpinning of the barriers, encountered in practice in moving to high-grade recycling in material chains. This fills the knowledge gap that was identified by Ritzen and Olundh Sandström [19] on the basis of their literature study. Instead of identifying a list of practical barriers as Ritzen and Olundh Sandström [19] did, a process-oriented approach was followed. This generated the above insights that complement the mostly conceptual or theoretical literature on the transition towards high-grade recycling and the circular economy in general. The empirical analysis revealed that the five key drivers identified follow a certain sequence in implementation and circumvent the three fundamental barriers each in their own way. By linking these key drivers in a conceptual model to the three fundamental barriers that inhibit the transition to a circular economy, it is revealed how the latter barriers can be circumvented in practice and the four key conditions for successful implementation are met. The above conclusions are based on the Dutch context. It would be useful to assess whether similar key drivers can be identified in other socio-political contexts, and whether similar change processes need to be put in place to accelerate high-grade recycling. It might very well be that the particular Dutch sociopolitical culture of multi-stakeholder cooperation (called the 'polder model') enables the change processes as described above. In other cultures where government plays a more steering role or where the market is in the driver's seat, the approach to implement circular initiatives may be different [41]. However, in all socio-political cultures the transition towards a circular economy will not be business as usual. It requires a shift towards a new economy that safeguards the sustainability of human life on Earth. In this respect, humanity faces a similar challenge worldwide. 
Acknowledgments: The author likes to thank the referees for their valuable comments. Their critical remarks encouraged me to improve the draft paper and further deepen the analysis.

Conflicts of Interest: The author declares no conflict of interest.

\section{References}

1. Allwood, J.M.; Ashby, M.F.; Gutowski, T.G.; Worrell, E. Material-efficiency: A White Paper. Resour. Conserv. Recycl. 2013, 55, 362-381. [CrossRef]

2. Dobbs, R.; Oppenheim, J.; Thompson, F.; Brinkman, M.; Zornes, M. Resource Revolution: Meeting the World' Energy, Materials, Food and Water Needs; McKinsey Global Institute: New York, NY, USA, 2011.

3. Ellen MacArthur Foundation. Towards the Circular Economy, Economic and Business Rationale for an Accelerated Transition; Ellen MacArthur Foundation: Cowes, UK, 2013.

4. Ghisellini, P.; Cialani, C.; Ulgiati, S. A Review on Circular Economy: The Expected Transition to a Balanced Interplay of Environmental and Economic Systems. J. Clean. Prod. 2016, 114, 11-32. [CrossRef]

5. Sauvé, S.; Bernard, S.; Sloan, P. Environmental Sciences, Sustainable Development and Circular Economy: Alternative Concepts for Transdisciplinary Research. Environ. Dev. 2016, 17, 48-56. [CrossRef]

6. Boulding, K.E. The Economics of the Coming Spaceship Earth. In Environmental Quality in a Growing Economy; Jarrett, H., Ed.; Johns Hopkins Press: Baltimore, MD, USA, 1966; pp. 3-14, ISBN 978-1-61726-027-8.

7. Pearce, D.; Turner, R. Economics of Natural Resources and the Environment; Johns Hopkins Press: Baltimore, MD, USA, 1989.

8. Von Bertalanffy, L. An Outline of General System Theory. Br. J. Philos. Sci. 1950, 2, 134-165. [CrossRef]

9. Ayres, R.U. Industrial Metabolism. In Technology and Environment; Ausubel, J.H., Sladovich, H.E., Eds.; National Academy Press: Washington, DC, USA, 1989; pp. 23-49, ISBN 978-0-309-04426-4.

10. Zhang, Y. A Review of Industrial Symbiosis Research: Theory and Methodology. Front. Earth Sci. 2015, 9, 91-104. [CrossRef]

11. Frosch, R.A. Industrial Ecology: A Philosophical Introduction. Proc. Natl. Acad. Sci. USA 1991, 89, 800-803. [CrossRef]

12. Graedel, T.E.; Allenby, B.R. Industrial Ecology; Prentice Hall Inc.: Upper Saddle River, NJ, USA, 1995.

13. Stahel, W.R. Langlebigkeit und Material-Recycling: Strategien zur Vermeidung von Abfällen im Bereich der Produkte; Vulkan-Verlag: Essen, Germany, 1991.

14. Braungart, M.; McDonough, W. Cradle to Cradle: Remaking the Way We Make Things; North Point Press: New York, NY, USA, 2002.

15. Ellen MacArthur Foundation. SUN and McKinsey Center for Business and Environment. In Growth Within: A Circular Economy Vision for a Competitive Europe; Ellen MacArthur Foundation: Cowes, UK, 2015.

16. Nguyen, H.; Stuchtey, M.; Zils, M. Remaking the Industrial Economy. McKinsey Q. 2014, 1, 46-63.

17. Van Nes, C.N.; Cramer, J.M. Product Lifetime Optimization: A Challenging Strategy towards more Sustainable Consumption Patterns. J. Clean. Prod. 2006, 14, 1307-1318. [CrossRef]

18. Söderholm, R.; Tilton, J.E. Material Efficiency: An Economic Perspective. Resour. Conserv. Recycl. 2012, 61, 75-82. [CrossRef]

19. Ritzén, S.; Olundh Sandström, G. Barriers to the Circular Economy-Integration of Perspectives and Domains. Procedia CIRP 2017, 64, 7-12. [CrossRef]

20. Hagelüken, C.; Lee-Shin, J.U.; Carpentier, A.; Heron, C. The EU Circular Economy and Its Relevance to Metal Recycling. Recycling 2016, 1, 242. [CrossRef]

21. Lansink, A. Challenging Changes; Connecting Waste Hierarchy and Circular Economy; LEA: Nijmegen, The Netherlands, 2017; ISBN 978-90-821783-5-7.

22. Utrecht Sustainability Institute: Circular Economy Labs (since 2013 till Present); All Collaborative Workshops Reported via Video, Report and Article (in Dutch). Available online: https://www.usi.nl/en/circulareconomy / circular-economy-labs (accessed on 19 July 2017).

23. Tietenberg, T.; Lewis, L. Environmental and Natural Resource Economics; Routledge: New York, NY, USA, 2018.

24. Owen, A.D. Environmental Externalities, Market Distortions and the Economics of Renewable Energy Technologies. Energy J. 2004, 25, 127-156. [CrossRef]

25. Heshmati, A. A Review of the Circular Economy and Its Implementation; Discussion Paper No. 9611; IZA: Bonn, Germany, 2015. 
26. Ruggieri, A.; Braccini, A.M.; Poponi, S.; Mosconi, E.M. A Meta-Model of Inter-Organisational Cooperation for the Transition to a Circular Economy. Sustainability 2016, 8, 1153. [CrossRef]

27. Zhijun, F.; Nailing, Y. Putting a Circular Economy into Practice in China. Sustain. Sci. 2007, 2, 95-101. [CrossRef]

28. Geng, Y.; Doberstein, B. Developing the Circular Economy in China: Challenges and Opportunities for Achieving 'Leapfrog Development'. Int. J. Sustain. Dev. World Ecol. 2008, 15, 231-239. [CrossRef]

29. De Römph, T.J. The Legal Transition towards a Circular Economy; EU Environmental Law Examined; Hasselt University: Leuven, Belgium, 2018.

30. Kunz, N.; Atasu, A.; Mayers, K.; Van Wassenhove, L. Extended Producer Responsibility: Stakeholder Concerns and Future Developments; INSEAD, Social Innovation Centre and European Recycling Platform: Fontainebleau, France, 2014.

31. Ellen MacArthur Foundation. Towards the Circular Economy Vol. 3: Accelerating the Scale-Up Across Global Supply Chains; Ellen MacArthur Foundation: Cowes, UK, 2014.

32. Suez Circular Economy Zone. Few Products Contain Recycled Plastics-Are Consumers Part of the Problem? Available online: https: / www.theguardian.com/.../few-products-contain-recycled-plastics-areconsumerspartoftheproblem? (accessed on 26 July 2017).

33. Ministry of Housing, Spatial Planning and the Environment (VROM). Notitie Inzake Preventie en Hergebruik van Afvalstoffen; Report on Prevention and Reuse of Waste Products; House of Representatives: Washington, DC, USA, 1988.

34. Mulder, L. High Quality Recycling of Construction and Demolition Waste in the Netherlands; Utrecht University: Utrecht, The Netherlands, 2013.

35. Cramer, J. Green Deal Cirkelstad; Voorwaarden voor een Marktconforme Aanpak; Green Deal Circle City, Conditions for a Competitive Approach; Utrecht Sustainability Institute, Ministry of Infrastructure and Environment and Circle City: Utrecht, The Netherlands, 2015.

36. Cramer, J. Van Cirkelstad Naar Cirkelland; From Circle City to Circle Country; Utrecht Sustainability Institute: Utrecht, The Netherlands, 2014.

37. Buchanan, D.; Badham, R. Power, Politics and Organizational Change; Winning the Turf Game; Sage: Los Angeles, CA, USA, 2008.

38. Witjes, S.; Lozano, R. Towards a more Circular Economy: Proposing a Framework Linking Sustainable Public Procurement and Sustainable Business Models. Resour. Conserv. Recycl. 2016, 112, 37-44. [CrossRef]

39. Pomponi, F.; Moncaster, A. Circular Economy for the Built Environment: A Research Framework. J. Clean. Prod. 2017, 143, 710-718. [CrossRef]

40. Grin, J.; Rotmans, J.; Schot, J. Transitions to Sustainable Development; Routledge: New York, NY, USA; London, UK, 2010; ISBN 9780415876759.

41. McDowall, W.; Geng, Y.; Huang, B.; Barteková, E.; Bleischwitz, R.; Türkeli, S.; Kemp, R.; Doménech, T. Circular Economy Policies in China and Europe. J. Ind. Ecol. 2017, 21, 651-661. [CrossRef] 